\title{
Um lugar de representação pela língua: o programa de leitorado do Ministério das Relações Exteriores brasileiro ${ }^{1}$
}

Leandro Rodrigues Alves Diniz (UNILA / UNICAMP)

${ }^{1}$ Este artigo retoma algumas das discussões feitas em minha pesquisa de doutorado (DINIZ, no prelo), desenvolvida na Universidade Estadual de Campinas (Unicamp), sob orientação da Profa. Dra. Mónica G. Zoppi-Fontana e co-orientação da Profa. Dra. Matilde V. R. Scaramucci. Agradeço à Fundação de Amparo à Pesquisa do Estado de São Paulo (FAPESP) pela bolsa concedida entre setembro de 2008 e agosto de 2010 (processo no. 07/59045-2). Agradeço, ainda, à Coordenação de Aperfeiçoamento de Pessoal de Nível Superior (CAPES), que me possibilitou realizar um estágio de doutorado na Université Sorbonne Nouvelle - Paris III, entre setembro de 2010 e março de 2011 (processo no. 2026-10-4).

\section{Resumo}

A partir do quadro teórico-metodológico da História das Ideias Linguísticas, na sua relação com a Análise do Discurso materialista, analisamos alguns aspectos relativos à política linguística exterior brasileira, especificamente, o imaginário que significa o leitor do Ministério das Relações Exteriores, oficialmente definido como "o professor universitário, de nacionalidade brasileira, que se dedica ao ensino da lingua portuguesa falada no Brasil, e da cultura e da literatura nacionais em instituições universitárias estrangeiras" (BRASIL, 2006). É possivel observar uma heterogeneidade em seu campo de atuação, indicativa do fato de que os leitorados estão subordinados antes às instituições estrangeiras do que ao Estado brasileiro. Além disso, os leitores tendem a ser significados como representantes do Brasil, a despeito de uma polêmica sobre o que / quem devem representar. Constrói-se, assim, através da lingua nacional, enquanto signo da cultura brasileira, um lugar de representação cultural e/ ou diplomática do Brasil.

Palavras-chave: português como língua estrangeira; política linguística exterior brasileira; leitorado 


\section{Introdução}

A política linguística exterior do Estado brasileiro tem sido levada a cabo, essencialmente, pelo Ministério da Educação (MEC) e pelo Ministério das Relações Exteriores (MRE). Dentre as ações do primeiro, destaca-se a criação do Certificado de Proficiência e Língua Portuguesa para Estrangeiros (Celpe-Bras), aplicado, em 2011, em cerca de 20 centros no Brasil e 45 no exterior, espalhados por mais de 25 países (BRASIL, 2011). O MRE, por sua vez, atua na promoção do português através da Rede Brasileira de Ensino no Exterior (RBEx), composta por Centros Culturais Brasileiros, Institutos Culturais Bilaterais e leitorados brasileiros. A RBEx é, atualmente, subordinada à Divisão de Promoção da Língua Portuguesa (DPLP), que, por sua vez, pertence ao Departamento Cultural do Itamaraty.

No presente artigo, objetivamos analisar, especificamente, a rede de leitorado, que, conforme apresentação disponível no site do $\mathrm{MRE}^{2}$, "reúne professores especialistas em língua portuguesa, literatura e cultura brasileiras, que atuam em conceituadas universidades estrangeiras" ${ }^{\prime \prime}$. Os primeiros leitorados brasileiros, segundo Silva e Gunnewiek (1992), foram criados na França e Inglaterra, na década de 1960. Essa modalidade de difusão do português tem crescido significativamente nos últimos anos: em 2004, a RBEx contava com 32 leitores; em 2011, com 68. Ainda conforme dados disponíveis no site do Itamaraty, 64 instituições estrangeiras, presentes em 41 países, contavam, em dezembro de 2011, com pelo menos um leitor do MRE, atendendo a mais de 3600 alunos.

O exercício da atividade de leitorado, de acordo com a portaria que atualmente regulamenta o programa (BRASIL, 2006), é de dois anos, podendo ser prorrogado uma única vez, por igual período. A seleção dos leitores, feita por meio da análise dos currículos dos candidatos, é de responsabilidade de três entidades, a saber: o MRE, a Coordenação de Aperfeiçoamento de Pessoal de Nível Superior (CAPES/MEC) e a instituição estrangeira. Ao longo deste artigo, analisaremos, especificamente, os discursos que, historicamente, significam a figura do leitor, a fim de melhor compreender o funcionamento dessa vertente da política linguística exterior do Estado brasileiro.

Inicialmente, apresentaremos brevemente nosso quadro

2 Cf. <http://www. dc.mre.gov.br/lingua-e-literatura>. Acesso em 21 nov. 2011.

3 Cf.: <http://www. dc.mre.gov.br/outras-noticias/conheca-o-departamento-cultural>, especificamente, o link "leitorados" da seção "língua e literatura". Acesso em: 01 dez. 2011. teórico-metodológico de referência: o da História das Ideias Linguísticas, na sua relação com a Análise do Discurso materialista. Passaremos, então, à discussão do imaginário sobre o leitor, atentando, inicialmente, para um pré-requisito indispensável para assumir tal função - a nacionalidade brasileira -, indicativo de que o leitor é significado como um representante (diplomático) do Brasil. Uma vez mostrada a diversidade de atividades desenvolvidas pelo leitor - que podem estar muito além daquelas 
previstas na portaria de 2006 -, chamaremos a atenção para uma polêmica em torno do que / de quem o leitor deve representar. Argumentaremos, porém, que, a despeito dessa polêmica, o leitor é, invariavelmente, significado como um representante cultural do Brasil. Por fim, apresentaremos, em nossas considerações finais, as principais conclusões que nosso percurso permite sustentar, sublinhando a relação indissociável entre o imaginário sobre o leitor e a história da construção da língua nacional brasileira.

\section{Considerações teórico-metodológicas}

Nosso estudo tem como referencial teórico-metodológico um novo campo de conhecimento, fundado na França na década de 80 - a História das Ciências da Linguagem -, que se consolidou no Brasil sob o nome de História das Ideias Linguísticas (HIL). Tal domínio se interessa pelas diferentes formas de constituição do saber metalinguístico ao longo da história, não se restringindo, portanto, àqueles desenvolvidos na chamada Linguística moderna. Nas palavras de Auroux (1992, p. 13), “Seja a linguagem humana, tal como ela se realizou na diversidade das línguas; saberes se constituíram a seu respeito; este é nosso objeto". Um conceito fundamental nesse campo é o de gramatização, definido como "o processo que conduz a descrever e a instrumentar uma língua na base de duas tecnologias, que são ainda hoje os pilares de nosso saber metalingüístico: a gramática e o dicionário" (ibidem, p. 65). Nessa perspectiva, a gramática e o dicionário, longe de serem uma mera descrição ou representação das línguas, são instrumentos linguísticos, que mudam os espaços-tempos "Assim como as estradas, os canais, as estradas-de-ferro e os meios de transporte, a gramatização modificou profundamente a ecologia da comunicação e o estudo do patrimônio lingüístico da humanidade", afirma Auroux (ibidem, p. 70), que lembra, por exemplo, que as línguas pouco ou menos instrumentalizadas foram mais expostas ao "linguicídio", voluntário ou não.

Ainda que assuma esse princípio de trabalho proposto por Auroux, bem como o conceito de gramatização, a HIL no Brasil guarda suas especificidades em relação à maneira como a área se desenvolveu na França, como podemos observar a partir da seguinte formulação de Guimarães e Orlandi (1996, p. 14):

Além da produção de um conhecimento específico necessário ao domínio lingüístico, importa conhecer o modo de formulação da língua nacional e o de constituição de um saber metalinguístico para melhor compreender a variada natureza dos objetos simbólicos que estão envolvidos na formação de um país como o Brasil. É da produção desses objetos e da relação estabelecida pelos sujeitos com essa produção que resultam os sentidos atribuídos ao país, assim como aqueles que dão sentidos a esses sujeitos enquanto eles se definem em relação ao seu país, 
nas formas que a política das relações sociais significar nessa sua história, seja como súditos, seja como escravos, seja como cidadãos.

Assim, os estudos brasileiros no campo da HIL, que estabelecem uma forte relação com a Análise do Discurso materialista, concebem a história da produção e circulação de um saber metalinguístico como indissociável da história da construção da língua nacional brasileira. A fim de investigar a maneira como o processo de instrumentalização do português participa da constituição dos Estados e identidades nacionais, estudam-se não apenas gramáticas e dicionários, mas também currículos, programas de ensino, vocabulários, acordos ortográficos, dentre outros instrumentos (cf. ORLANDI, 2001). Observa-se, portanto, uma ampliação do conceito de gramatização, que passa a se referir às diversas instâncias de instrumentalização de uma língua, para além da gramática e do dicionário. Além disso, a HIL no Brasil procura pensar a relação desse processo de gramatização com as instituições responsáveis pela sua produção e/ou circulação: academias, centros de pesquisa, colégios, associações científicas, imprensa, dentre outras. No presente artigo, concentramo-nos na aparelhagem institucional que participa da gramatização do português como língua estrangeira, através da análise dos leitorados, que desempenham um papel importante na produção e circulação, fora do Brasil, de saberes sobre "a língua portuguesa, a cultura e a literatura nacionais", para recuperar as palavras utilizadas no site do Itamaraty, anteriormente citadas.

Para o desenvolvimento de nosso estudo, tivemos, como corpus de pesquisa, os seguintes materiais, dentre outros: (i) portarias, editais e outros textos jurídicos referentes ao programa de leitorado; (ii) textos escritos por ex-leitores; (iii) e-mails relativos aos leitorados disponíveis no Intradocs, um sistema que armazena mensagens eletrônicas do Itamaraty enviadas após 1995, ao qual tivemos acesso em pesquisa de campo realizada na Coordenação de Documentação Diplomática (CDO) do MRE, em Brasília. Além disso, fazem parte de nosso corpus materiais de natureza experimental, a saber, entrevistas feitas com ex-leitores e com diplomatas do Itamaraty.

\section{Um pré-requisito necessário: a nacionalidade brasileira}

A Portaria $\mathrm{n}^{\mathrm{o}} .1$ de 20 de março de 2006 (BRASIL, 2006), que rege atualmente o programa de leitorado, define, em seu artigo primeiro, "o leitor brasileiro como o professor universitário, de nacionalidade brasileira, que se dedica ao ensino da língua portuguesa falada no Brasil, e da cultura e da literatura nacionais em instituições universitárias estrangeiras". O fato de que esse artigo procure definir a categoria de "leitor brasileiro" indica, possivelmente, que, embora os primeiros leitorados tenham sido criados na década de 1960, ainda havia, em 2006, uma necessidade institucional de normatizar essa função, contendo, de alguma 
forma, a deriva dos sentidos que a significam. Com efeito, nossas análises mostram que a figura do leitor é construída por diferentes sentidos, que estabelecem, inclusive, relações de polêmica entre si.

Observemos, inicialmente, que a expressão "o leitor brasileiro" é determinada pelo sintagma "de nacionalidade brasileira", o que pode produzir um efeito tautológico. Afinal, um leitor brasileiro não teria, logicamente, nacionalidade brasileira? Se colocarmos em relação o artigo $1^{\circ}$ da portaria de 2006 com o correspondente na portaria que, até esse ano, regulamentava o programa de leitorado (BRASIL, 1999) ${ }^{4}$, podemos perceber um movimento no sentido de caracterizar o leitor do Itamaraty pela nacionalidade brasileira:

O MINISTRO DE ESTADO DAS RELAÇÕES EXTERIORES, no uso de suas atribuições, RESOLVE:

Art. $1^{\circ}$ Leitor ${ }^{5}$ é o professor universitário que se dedica ao ensino do idioma português falado no Brasil, da cultura e da literatura brasileiras e como tal reconhecido por instituições universitárias estrangeiras e pelo Departamento Cultural do Ministério das Relações Exteriores (BRASIL, 1999).

Está em jogo, portanto, uma nova determinação que, a partir da portaria de 2006, passa a caracterizar, juridicamente, o leitor: esse deve ser de nacionalidade brasileira. Embora não tenhamos conhecimento de estrangeiros que, antes da portaria de 2006, tenham sido leitores do Itamaraty, essa modificação explicita uma característica que figura entre os poucos pré-requisitos estabelecidos pela portaria para o preenchimento do cargo de leitor: a nacionalidade brasileira. Elimina-se, assim, uma possibilidade de interpretação aberta pelo artigo $1^{\circ}$ da portaria de 1999: a de que não-brasileiros possam ser leitores do MRE.

O texto da portaria de 2006 permite, ainda, inferir dois

4 Portaria n. ${ }^{\circ}$, de 29 de março de 1999, publicada pela Divisão de Programas de Divulgação Cultural do MRE e revogada pela portaria de 2006.

5 A mudança na designação "leitor", no artigo $1^{\circ}$ da portaria de 1999 , para "leitor brasileiro", empregada na portaria de 2006, faz um ajuste técnico no texto, na medida em que há leitores de outros países, como os "Lektoren" do Instituto Goëthe, que, por intermédio do DAAD (Deutscher Akademischer Austauschdienst - Serviço Alemão de Intercâmbio Acadêmico), atuam em universidades do Brasil e de outros países. outros pré-requisitos. O primeiro deles é o de que o leitor tenha formação universitária, já que ele leciona em universidades; o segundo, de que ele conheça "a língua portuguesa falada no Brasil", bem como "a literatura e cultura nacionais". Cabe destacar, entretanto, que o primeiro desses pré-requisitos não foi, ao longo da história dos leitorados, indispensável para o preenchimento do cargo, já que, conforme informações dadas por (ex-) leitores, houve, antes da portaria de 1999, casos de leitores que não tinham formação universitária, mas que assumiam seus postos devido a indicações políticas. O segundo pré-requisito, por sua vez, parece, em certa medida, derivado daquela que representa a condição inexorável do leitor do Itamaraty: a nacionalidade brasileira. Devido ao próprio funcionamento do Estado Nacional - para cuja articulação simbólica a língua nacional desempenha um papel central -, define-se o leitor não por qualquer língua praticada no Brasil, mas sim pela "língua portuguesa falada no Brasil". Em outras palavras, é inconcebível um leitor do MRE que se dedique 
ao ensino de outras línguas que não essa. Dessa forma, o principal pré-requisito necessário para assumir o cargo de leitor é a nacionalidade brasileira - e o conhecimento da "língua portuguesa falada no Brasil, e da cultura e literatura nacionais", que, historicamente, aparece vinculado à constituição da nacionalidade. As demais características do leitor explicitadas na definição - ser professor universitário e dedicar-se às atividades de docência mencionadas no $\operatorname{artigo~} 1^{\circ}$ - incidem apenas sobre o trabalho desenvolvido, e não sobre outros pré-requisitos (por exemplo, de ordem acadêmica ou profissional) necessários para ocupar a função.

Colocamo-nos, então, a seguinte questão: que elementos da memória discursiva sustentam a exigência de que o leitor seja brasileiro? Para respondermos a essa pergunta, destaquemos, em primeiro lugar, que, embora a atividade do estrangeiro no Brasil sofra algumas restrições, conforme o artigo 106 do Estatuto do Estrangeiro (BRASIL, 1981), o artigo 207, parágrafo $1^{\circ}$, da Constituição Federal de 1988, incluído pela Emenda Constitucional no. 11 (idem, 1996), estabelece que "é facultado às universidades admitir professores, técnicos e cientistas estrangeiros, na forma da lei". O leitor não é, portanto, significado da mesma forma que outros cargos de docência universitária. Se assim fosse, estrangeiros com formação em língua portuguesa, literatura e cultura brasileiras - que, por vezes, ministram disciplinas nessas áreas, em cursos de graduação e pós-graduação no Brasil - poderiam assumir a função de leitor.

É preciso lembrar, ainda, que, conforme o parágrafo $3^{\circ}$ do artigo $12^{\circ}$ da Constituição Federal de 1988 (idem, 1988), alguns cargos são privativos de brasileiro nato; dentre eles, os da carreira diplomática. Tal fato nos parece particularmente importante para compreender as razões pelas quais o leitor deve ter nacionalidade brasileira. Enquanto função estabelecida no seio do Itamaraty, o leitor é caracterizado como um representante do Brasil, que, portanto, deve, necessariamente, ser brasileiro, assim como os membros da carreira diplomática. No entanto, à diferença destes, o leitor pode ser naturalizado, o que não invalida nossa hipótese de que ele seja significado, quanto à sua função, como um representante diplomático, já que, conforme o artigo $12, \S 2^{\circ}$ da Constituição de 1988, são vedadas distinções entre brasileiros natos e naturalizados, exceto para os cargos previstos nessa legislação.

No recorte abaixo, referente a uma entrevista que fizemos

${ }^{6}$ Entrevista realizada em Campinas, em 03 de maio de 2010. Agradecemos à professora pela gentileza com que nos concedeu esta entrevista e autorizou sua publicação. com a Profa. Dra. Ester Mirian Scarpa, leitora no King's College (Londres) entre setembro de 2003 e agosto de 2009', o leitor também é caracterizado como um representante diplomático:

eu acho que de fato os leitores têm que... não pode ser um cargo vitalício... não pode ser... [...] você manda daqui... a pessoa é mandada daqui pra uma missão... diplomática... 
Além da designação "missão diplomática", destacamos o uso da voz passiva ("a pessoa é mandada daqui..."), que reformula uma oração na voz ativa ("você manda daqui"). Não se trata, portanto, simplesmente, de uma iniciativa individual, mas de uma "missão" determinada por um agente que, embora não apareça explicitado no recorte acima, podemos inferir: o Itamaraty, enquanto célula do Estado brasileiro.

\section{Um cargo heterogêneo}

A portaria Interministerial de 20 de março de 2006 estabelece, em seu primeiro artigo, anteriormente transcrito, que o leitor "se dedica ao ensino da língua portuguesa falada no Brasil, e da cultura e da literatura nacionais em instituições universitárias estrangeiras" (BRASIL, 2006). Na prática, porém, sua atuação pode abranger diversas outras atividades (didáticas ou não) além das mencionadas na portaria, como indicam os perfis dos leitores especificados por cada universidade nos anexos dos editais de leitorado da CAPES. É possível perceber uma grande heterogeneidade nas atividades desenvolvidas pelos leitores, que podem compreender não apenas aulas de língua portuguesa, literatura e cultura brasileiras, como prevê a portaria, mas também de história, linguística, tradução, teoria literária e literatura de países africanos de língua portuguesa. Em alguns casos, o leitor ministra cursos de formação continuada de professores, elabora materiais didáticos para atividades presenciais ou a distância, orienta trabalhos acadêmicos e/ou aplica o exame de proficiência Celpe-Bras.

Além disso, o próprio espaço de atuação desse profissional não se restringe àquele previsto na portaria, uma vez que alguns leitores atuam em Embaixadas ou Centros Culturais Brasileiros, ao mesmo tempo em que desenvolvem suas atividades nas universidades. Há, ainda, casos de leitores que não trabalham em instituições de ensino superior. No primeiro semestre de 2008, por exemplo, foi aberta uma vaga para um leitor que trabalharia não em uma universidade da África do Sul, mas no atual Centro Cultural Brasil-África do Sul, enquanto, no segundo semestre de 2010, selecionaram-se leitores para atuar na Universidade de Cabo Verde e no Instituto Internacional da Língua Portuguesa (IILP), subordinado à Comunidade dos Países de Língua Portuguesa (CPLP). Frequentemente, os leitores tornam-se diretores ou coordenadores desses centros, assumindo, portanto, atividades que estão muito além da docência propriamente dita, como direção, coordenação ou mesmo administração e gestão.

Essa grande heterogeneidade parece evidenciar que o leitorado está subordinado antes à instituição estrangeira do que ao Itamaraty, que interfere pouco ou nada na determinação dos perfis dos leitores que preencherão as diferentes vagas. A diversidade das atividades desenvolvidas pelos leitores é, todavia, ainda maior do que uma análise dos perfis disponibilizados nos 
editais da CAPES nos leva a perceber. Os leitores chegam, em alguns casos, a ser concebidos como adidos culturais, conforme argumentaremos a seguir.

\section{Um representante cultural}

Discutimos, na seção anterior, que um pré-requisito fundamental para o exercício do leitorado é a nacionalidade brasileira, defendendo a hipótese de que essa exigência sinaliza uma filiação a sentidos que constroem para o leitor o lugar de um representante (diplomático) do Brasil. Na presente seção, gostaríamos de destacar que, em alguns casos, a identificação do leitor como um representante do Brasil é tão forte que ele chega a se caracterizar ou ser caracterizado como um membro da Embaixada - especificamente, como um adido ou attaché cultural. Vejamos, nesse sentido, como o leitor aparece significado na mensagem abaixo, enviada em 09 de fevereiro de 2004 pelo então Embaixador brasileiro em Acra (Gana) ${ }^{7}$, Paulo Americo V. Wolowski, e destinada à DPLP, Divisão da África I (DAF I) e Divisão de Temas Educacionais (DCE).

Como ficara acertado durante a visita do Professor Marco Aurélio Schaumloeffel à Brasil House em novembro de 2003, iniciaram-se, com sucesso, na 4 a feira, dia 4, os chamados Encontros Culturais, que acontecerão quinzenalmente, entre o representante da Embaixada, isto é, o Leitor brasileiro junto ao Instituto Ganense de Línguas da Universidade de Gana/ Legon e o povo brasileiro-ganense dos Tabom.

[...] Pessoalmente, creio que com os mencionados encontros solidifica-se o que sempre pretendi com relação à família brasileiro-ganense, isto é, institucionalizar os desejados e necessários vínculos entre a Embaixada e o clã, como por exemplo quando compareci à coroação do presente Mantse Nii Azumah Nelson, distanciando a relação bilateral de aspectos de ordem pessoal ou paternalista. [...]

Por outro lado, folgo ao ver quão necessária era a presença de um Leitor nesta Embaixada. Além das aulas regulares de português e civilização brasileira no IGL, o Professor Schaumloeffel, como já informei, mantém curso compacto de introdução ao idioma português para os estudantes ganenses selecionados ao PEC-G/2004, através do qual é possível a Embaixada rever sua seleção inicial, além do que comparece a eventos de ordem cultural, representante da Embaixada, aos quais tendo em conta seja a diminuta lotação desta Missão (só um diplomata), seja o excesso de atividades de ordem diversa (política, social, comercial, etc) fora da Embaixada que devo, primordialmente, comparecer, esta Missão diplomática não se faria presente [grifos nossos].

7Despacho telegráfico n. ${ }^{\circ} 00094$, a que tivemos acesso através do Intradocs, anteriormente mencionado.
Os encontros culturais organizados por Schaumloeffel, então leitor em Acra (Gana), permitem, conforme o recorte acima, "institucionalizar os desejados e necessários vínculos entre a Embaixada e o clã". Além disso, os benefícios que as atividades do 
${ }^{85}$ egundo informações do próprio ex-leitor em Gana, Schaumloeffel (2005), os Tabom são uma comunidade de descendentes de escravos que voltaram do Brasil, chegando a Acra no ano de 1836. A designação "o povo brasileiro-ganense", empregada no telegrama, faz referência ao modo como, conforme o autor (ibidem), os Tabom se auto-denominam ao se apresentarem. leitor podem trazer, em termos de relação bilateral, chegam a ser equiparados aos de atividades do Embaixador, como a presença deste último na cerimônia de coroação do chefe (Mantse) da comunidade dos Tabom ${ }^{8}$, Nii Azumah V. A imagem que se constitui, então, para o leitor é a de um membro da Missão Diplomática, que, enquanto tal, pode, inclusive, representá-la em eventos culturais em que o Embaixador esteja ausente.

Todavia, é importante observar, tendo em vista o jogo de projeções imaginárias que, segundo Pêcheux (1997), preside a troca de palavras, que a denotação da expressão nominal "o representante da Embaixada" não é evidente, segundo a imagem que, por antecipação, o sujeito-locutor faz da imagem do referente para o sujeito-interlocutor. O sentido desse sintagma é "ajustado" através do uso do operador "ou seja", que introduz uma nova designação: "Leitor brasileiro junto ao Instituto Ganense de Línguas da Universidade de Gana/Legon". Tal fato é indicativo de que a função de leitor não está diretamente associada à de representante da Embaixada, nem mesmo para os membros da DPLP, DAF I e DCE, destinatários do telegrama. Independentemente disso, interessa-nos destacar que a imagem que se constrói em relação ao leitor é a daquele que pode inclusive representar a Embaixada. Semelhantemente, Gohn (2006), ex-leitor na Índia, caracteriza os leitores como profissionais que podem fazer as vezes de um adido cultural, em benefício da diplomacia cultural brasileira:

[Somos] o único país latino-americano a ter leitorado na Índia, em Delhi e em Goa. Esse fato [...] dá algumas vantagens estratégicas para iniciativas de diplomacia cultural, uma vez que a Embaixada pode contar com o leitor para atividades que seriam normalmente próprias de um adido cultural [grifo nosso].

Entretanto, alguns, como Serravalle de Sá, leitor na Universidade de Manchester (Inglaterra) entre 2007 e 2010, discordam de semelhante visão, afirmando que as atividades do leitor devem se restringir ao âmbito acadêmico.

Acredita-se que o trabalho do Leitor consiste em, obviamente, disseminar a língua portuguesa na variante brasileira. Além disso, caberia ao Leitor organizar simpósios, eventos culturais e literários, promover mostras de cinema nacional, divulgar o exame CELPE-Bras (exame de proficiência do português brasileiro) e trabalhar para a consolidação do Leitorado brasileiro dentro da sua instituição e no mundo. Não se nega que o cargo de Leitor é um instrumento de política cultural, mas se crê que cabe apenas à Embaixada ser o representante oficial para informações e assessoria sobre o Brasil, junto à mídia ou Foreign Office. O Leitor não deveria querer ser adido cultural, pois seu âmbito de atuação é o acadêmico (SERRAVALLE DE SÁ, 2009, p. 36) [grifo nosso]. 
O recorte acima dá indícios de uma polêmica, na medida em que nega o discurso do outro. A fim de ilustrar esse funcionamento, contrapomos, no quadro abaixo, alguns enunciados:

\section{Posição Discursiva 1}

"A Embaixada pode contar com o leitor para atividades que seriam normalmente próprias de um adido cultural" (GOHN, 2006)

"[O leitor] comparece a eventos de ordem cultural, representante [representando] a Embaixada" (telegrama do Embaixador Wolowski, anteriormente apresentado)

\section{Posição Discursiva 2}

“[...] o Leitor não deveria querer ser um adido cultural, pois seu âmbito de atuação é o acadêmico." (SERRAVALLE DE SÁ, 2009, p. 36)

"Cabe apenas à Embaixada ser o representante oficial para informações e assessoria sobre o Brasil, junto à mídia ou Foreign Office" (SERRAVALLE DE SÁ, loc. cit.)

Tendo em vista a análise do funcionamento discursivo da negação proposta por Indursky (1997), poderíamos afirmar que o enunciado "O leitor não deveria querer ser um adido cultural" é "dividido", para usar o termo de Courtine (1982, p. 254-262), uma vez que, sob sua aparente unidade, veicula diferentes posições-sujeito. Na primeira delas, concebe-se o leitor como um representante da Embaixada brasileira, que pode assumir atividades típicas de um adido cultural. Na segunda posição, por outro lado, recusa-se semelhante perspectiva, restringindo o trabalho do leitor à esfera acadêmica.

O emprego do operador argumentativo "apenas" no enunciado "Cabe apenas à Embaixada ser o representante oficial para informações e assessoria sobre o Brasil, junto à mídia ou Foreign Office" também dá indícios dessa polêmica, uma vez que nega uma formulação de outra posição discursiva: "Os leitores também podem ser representantes oficiais para informações e assessoria sobre o Brasil, junto à mídia ou Foreign Office". Com efeito, no enunciado retirado do telegrama do Embaixador Wolowski, anteriormente reproduzido, está posta a possibilidade de o leitor representar a Embaixada em eventos culturais. Semelhantemente, no recorte a seguir, referente à entrevista com Scarpa, ex-leitora em Londres, o leitor é caracterizado como "porta-voz" do Brasil junto à mídia, em um evento como o Ano do Brasil na Inglaterra, em 2004:

houve o Ano do Brasil na Inglaterra... no ano seguinte foi na França... BBC vai procurar quem? vai entrevistar... vai ser o porta-voz... o leitor de onde? do leitorado em Londres que mais... que tem o contato mais... mais íntimo... com a Embai- 
xada... que é o King's College... tô lá eu sendo entrevistada...

Está em questão, portanto, o espaço de atuação dos leitores. Para a posição a partir da qual enuncia Serravalle de Sá, esse espaço se restringe ao âmbito acadêmico. Segundo outra posição, entretanto, há outros espaços de atuação do leitor, conforme o seguinte recorte da entrevista com Scarpa:

Entrevistador: e... você acha que as atividades... as atividades do leitor deveriam estar restritas ao âmbito universitário... à docência?

Entrevistada: não necessariamente... não... fica mais fácil né? essa divulgação... normalmente são espaços mais óbvios... mas não necessariamente... eu acho que os CEBs [Centros de Estudos Brasileiros] fazem... um papel excelente... em Londres tinha dois... um deles era o... BCA... Brazilian Contemporary Art... que era uma espécie de CEB... local... [...] lá por exemplo seria um espaço que poderia ter leitor... só que o leitorado é algo normalmente caro... então eles mandam o leitor pra onde tem uma certa visibilidade... e o leitor tem também... veja... além de dar aula... tem esse papel de ser um representante sim cultural do seu país lá... eu falei... nós somos procurados pra várias coisas... uma vez procuraram pra... pra... pra correção... foi pra... acho que foi pra correção...não foi elaboração... mas poderia ser elaboração... das provas de português dos diplomatas britânicos que queriam vir servir o Brasil... enfim... a coisa mais óbvia é... bom ensino de português brasileiro onde tem? tem tem muito brasileiro dando aula de português... muito muito curso... espontâneo... informal... muitos professores... muitos eh muitas pessoas que dão aula de português brasileiro... muitas pessoas... digamos físicas dando aula de português brasileiro... professores particulares etc... as escolas agora... têm algumas têm assessoria... tem essas firmazinhas de assessoria de língua... que oferecem então... o professor brasileiro vai na casa de alguém... e nós sempre somos procurados... conhece alguém que... tem que fazer um... uma tradução... não sei o quê... quer dizer... hoje em dia há outros espaços né? sociais... mercadológicos... ou públicos enfim... desse trabalho... que o Brasil é muito mais visível... muito mais visível... muito mais gente quer aprender português brasileiro... mas o o... a ligação mais óbvia é a do leitor... é a do leitor... é o representante do país lá...

Na perspectiva de Scarpa, os leitores poderiam desenvolver

${ }_{9}^{9}$ Os CEBs de que fala Scarpa, neste momento da entrevista, não são os Centros de Estudos Brasileiros (atualmente Centros Culturais Brasileiros) ligados ao Itamaraty, mas sim instituições estrangeiras que se dedicam a pesquisas e eventos relacionados à cultura brasileira. suas atividades em Centros de Estudos Brasileiros ${ }^{9}$ em vez de universidades. Este ponto nos parece, entretanto, de menor importância na análise da polêmica em questão, na medida em que esses centros também desenvolvem algumas atividades de caráter mais acadêmico. Afirmaríamos, inclusive, que, possivelmente, esse ponto de vista também seria expresso pela posição-sujeito aqui exemplificada pelos enunciados de Serravalle de Sá. O que nos parece particularmente interessante é a imagem do leitor enquanto um representante cultural do Brasil no exterior, construída na fala 
deScarpa. A esse respeito, cabe observar que, no enunciado "além de dar aula... tem esse papel de ser um representante sim cultural do seu país lá...", o emprego do operador argumentativo "além de" articula dois elementos de uma mesma escala argumentativa (cf. GUIMARÃES, 1987), de forma que as atividades de docência e de representação cultural são significadas como tendo o mesmo valor. É devido a essa imagem que, segundo Scarpa, se procuram os leitores - e não outras pessoas (físicas ou jurídicas) que, cada vez mais, se ocupam de atividades relacionadas ao ensino de português - para a realização de determinados trabalhos, como a correção de provas de português feitas por diplomatas britânicos.

Dessa forma, segundo a posição da última entrevistada, o espaço de atuação do leitor não é apenas aquele de natureza acadêmica, como as universidades e os CEBs, mas se estende, no limite, ao próprio país em que o leitor se encontra. Nesse sentido, podemos atentar para o uso do advérbio "lá" em "tem esse papel de ser um representante sim cultural do seu país lá..." e "é o representante do país lá...", que amplia sobremaneira o espaço de atuação do leitor, tornando-o, em certa medida, difuso. Não deixa de ser interessante o deslize entre o uso do artigo indefinido e definido nesses enunciados, o que, no fim do recorte, reforça a imagem do leitor enquanto representante cultural do Brasil: não se trata de um dentre outros representantes, mas do representante, considerado a "ligação mais óbvia" entre o Brasil e, no caso, a Grã-Bretanha.

Embora possamos, portanto, identificar duas posições discursivas relativas à maneira como a figura do leitor é significada, ambas caracterizam o cargo do leitor como relacionado à política cultural, conforme podemos observar através dos seguintes recortes:

Narra-se aqui um relato da experiência do autor como um agente de diplomacia cultural (GOHN, 2006) [grifo nosso].

Este artigo faz considerações sobre a política linguística do governo brasileiro à luz do programa de Leitorado em Manchester (Inglaterra). O que se oferece é um depoimento da experiência do autor enquanto um agente dessa política cultural. Reflete-se aqui sobre questões em torno da política linguística cultural brasileira e do ensino de português como língua estrangeira. (SERRAVALLE DE SÁ, 2009, p. 31) [grifo nosso].

No texto de Serravalle de Sá (ibidem), encontramos, inclusive, uma negação que parece refutar um simulacro que poderia ser construído pelo discurso do outro: o de que se opor à atuação do leitor enquanto adido cultural implique negar que ele seja um instrumento da política cultural brasileira.

Não se nega que o cargo de Leitor é um instrumento de política cultural, mas se crê que cabe apenas à Embaixada ser o representante oficial para informações e assessoria sobre o Bra- 
sil, junto à mídia ou Foreign Office (ibidem, p. 36) [grifo nosso].

Cabe atentar para o fato de que, no recorte anterior, se recusa ao leitor o papel de representante oficial do Brasil - mas não o de representante do Brasil. Com efeito, ao argumentar que as condições oferecidas para os leitores são inferiores a outras bolsas subsidiadas por agências de fomento, Serravalle de Sá chega a afirmar inclusive que o leitor brasileiro é um cargo de representação - e, nesse sentido, não faz número com um bolsista de doutorado pleno no exterior da CAPES:

Tal falta de "isonomia" é difícil de compreender, pois o Leitor brasileiro é um cargo representativo, responsável por ministrar aulas e pela divulgação da cultura brasileira no exterior coisa que o bolsista CAPES não tem a obrigação de fazer (ibidem, p. 33) [grifo nosso].

A polêmica incide, portanto, não sobre o fato de o leitor ser ou não um cargo de representação cultural - há um consenso entre as diferentes posições discursivas a esse respeito--, mas sobre o que / quem o leitor deve representar. Especificamente, existe uma polêmica sobre a imagem do leitor enquanto representante do Estado brasileiro - razão pela qual se recusa, na posição de Serravalle de Sá, a ideia de que esse profissional seja um adido cultural -, mas não sobre sua imagem de representante da cultura brasileira. $\mathrm{O}$ recorte abaixo, feito em uma entrevista que realizamos com um diplomata do Itamaraty ${ }^{10}$, é particularmente elucidativo a esse respeito.

10 Entrevista realizada em Brasília, em 24 de março de 2010, com um diplomata brasileiro que preferiu não ser identificado. eu acho que idealmente ele [o leitor] deveria ser uma espécie de... eh de adido cultural... [segmento ininteligível] ou algo parecido com isso... no sentido de... é que adido cultural pode passar a impressão de que é um representante do Estado né? a gente manda sempre os diplomatas... mas tem também o adido militar... que é das Forças Armadas... o adido policial... que é policial... o adido... por aí vai... e ele... ele tá lá representando o Governo... ele é pago pelo governo... o leitor também tá representando o Governo mas digo...

De maneira semelhante ao que observamos na análise da mensagem do ex-Embaixador em Gana, Wolowski, a designação "adido cultural" é representada como "imperfeita" para qualificar a atividade do leitor, como sinalizam algumas expressões de modalização autonímica (AUTHIER-REVUZ, 1998): "eu acho que idealmente ele deveria ser uma espécie de... eh de adido cultural... [segmento ininteligível] ou algo parecido com isso". Na sequência desse enunciado, o dizer continua voltando-se para si próprio (cf. "no sentido de..."), sinalizando uma falha entre a palavra e a coisa (cf. "é que adido cultural pode passar a impressão de que é um representante do Estado né?"). Elimina-se, assim, um sentido inoportuno que poderia ser favorecido pelo emprego da expressão "adido cultural" como forma de qualificar o leitor. $\mathrm{O}$ 
fato de que essa designação seja, sistematicamente, caracterizada como "imperfeita" na entrevista com o diplomata é compreensível se tivermos em vista que, a partir da posição ele enuncia, não é possível defender a legitimidade de representação do Estado brasileiro por uma pessoa não instituída formalmente como tal pelo Instituto Rio Branco. Esse sentido insiste, entretanto, em retornar no fio do discurso (cf. "o leitor também tá representando o Governo"), mas se observa, logo em seguida, uma inversão na direção argumentativa, através do operador "mas", e uma nova operação de fixação semântica, sinalizada por "digo". Significa-se, então, o leitor como "um representante da... da sociedade brasileira... do povo brasileiro... portanto da cultura... da civilização...", conforme podemos observar na continuação da entrevista:

acho que a ideia principal é que ele seja um... um representante da... da sociedade brasileira... do povo brasileiro... portanto da cultura... da civilização... e acho que isso tem que fazer sim... entendeu?... varia... alguns acham isso menos ou mais importante mas... mas acho que o leitor não deveria ser APENAS um professor de... de língua... ou que seja... de língua e civilização...

Estabelece-se, no recorte anterior, uma escala de valores, em que a atuação do leitor enquanto um professor de lingua ocupa um lugar de menor importância quando comparado ao trabalho enquanto docente de língua e civilização, conforme sinaliza o operador argumentativo "que seja". O valor máximo do trabalho do leitor seria atingido nos casos em que sua atuação se aproxima da de um adido cultural, como indica o início da resposta do entrevistado, anteriormente transcrito: "eu acho que idealmente ele deveria ser uma espécie de... eh de adido cultural...".

Na continuação da entrevista, o emprego do verbo "saber" dá indícios de um pré-construído que, justamente, está em funcionamento nos diferentes discursos sobre o papel do leitor: o de que esse representa o Brasil e o seu povo, sendo-lhes um "avatar", sobretudo em países onde há poucos brasileiros.

acho que ele tinha que saber que ele tá lá representando... o Brasil como um todo... que as pessoas vão ver nele um... uma pequena imagem... um avatar do que é o Brasil... do povo... as pessoas não vão olhar pra ele e olhar o governo... [segmento ininteligível]... ... as pessoas vão ver nele e imaginar o povo por trás dele... ainda mais... em lugares onde há poucos brasileiros... como o Vietnã... talvez a França isso não seja tão forte... mas em países onde há poucos brasileiros... acho que esse papel de... adido entre aspas... da sociedade pelo menos... se torna mais importante... acho que isso deveria ser feito sim...

Ao ser comparado a um avatar, o leitor é significado metonimicamente, já que seu trabalho garantiria a presença do Brasil em outro Estado Nacional. Ratifica-se, então, que o leitor é uma "pequena imagem" do povo brasileiro, razão pela qual se afirma que ele tem o papel de um adido cultural. Cabe observar, porém, 
que, através da oralização de um sinal tipicamente gráfico - as aspas -, a designação "adido cultural" é, novamente, significada, de certa forma, como imprópria, na medida em que o leitor representaria, nessa perspectiva, não o Estado, mas a sociedade.

\section{Considerações finais}

Em um momento inicial deste artigo, mostramos que as portarias de 1999 e 2006 restringem a atuação do leitor ao ensino das chamadas língua, cultura e literatura nacionais em universidades estrangeiras. Entretanto, vimos que as atividades desenvolvidas no âmbito desse programa podem compreender muitas outras. Considerando essa diversidade, Scarpa, na entrevista que nos concedeu, afirma que o leitor "tem que mimetizar", "tem que se adaptar ao local onde está... ao departamento onde está...", sendo esse um "cargo camaleão", "ambíguo" e "multifacetado".

Tal heterogeneidade indica que os leitorados estão subordinados antes às universidades estrangeiras do que ao Estado brasileiro, o que acaba por conferir um menor grau de coesão à chamada rede de leitorado. Nesse sentido, não há uma maior centralização por parte do Estado brasileiro no que diz respeito à política exterior levada a cabo por meio dos leitorados. Isso também fica claro se tivermos em vista que é a instituição estrangeira que estabelece o perfil do candidato a ser pré-selecionado pela CAPES, competindo-lhe, ainda, a decisão final quanto à escolha do leitor. É possível, inclusive, que a instituição estrangeira rejeite os candidatos pré-selecionados à vaga - caso em que o auxílio financeiro oferecido pelo Itamaraty é cancelado até nova seleção.

Além disso, defendemos a hipótese de que, enquanto cidadão brasileiro, o leitor do MRE é significado como um representante do Estado ou da cultura brasileira. Um indício de tal imagem reside, como argumentamos, em um pré-requisito indispensável para se assumir tal função: a nacionalidade brasileira. Estabelece-se, portanto, uma restrição a estrangeiros, evidenciando que não está em jogo, simplesmente, o "ensino da língua portuguesa falada no Brasil, e da cultura e da literatura nacionais" - para recuperar as palavras constantes na portaria de 2006 -, mas essa docência enquanto lugar de representação do Brasil no exterior. Assim como um diplomata do Itamaraty, um leitor não pode ser estrangeiro.

Cabe lembrar, entretanto, que, se por um lado, o leitor do MRE deve ter nacionalidade brasileira - o que implica que ele pode ser nato ou naturalizado -, por outro, um diplomata deve, necessariamente, ser nato. Assim, em que pesem os pontos de aproximação entre os dois cargos - que, conforme argumentamos, acabam por significar, em certa medida, o leitorado como um espaço de representação diplomática -, há uma diferença importante entre ambos. Tal tensão parece ir ao encontro daquela anteriormente observada: embora haja um consenso em relação à ideia de que o leitor seja um representante cultural, há uma 
polêmica concernente a de quem/ do que o leitor é representante. Para uma posição discursiva, o leitor pode participar de eventos diplomáticos, a exemplo da organização de eventos de recepção ao presidente do Brasil, bem como dar informações junto à mídia ou ao Ministério das Relações Exteriores, mesmo que essas atividades não digam respeito ao leitorado propriamente dito. O leitor aparece, assim, concebido como um representante da Embaixada ou como um adido cultural, que pode atuar como porta-voz do Estado brasileiro no exterior, enquanto intermediário entre o último e o Estado em que desenvolve suas atividades. Para outra posição discursiva, não cabe ao leitor o papel de representante do Estado brasileiro, ainda que lhe caiba o de representante do povo brasileiro e de sua cultura.

Dessa forma, constrói-se, através da língua - enquanto signo da cultura brasileira -, um lugar de representação do Brasil. A língua que permite essa representação, cabe sublinhar, não é qualquer língua falada no país, mas aquela que, historicamente, participou da construção do ideal de unidade do Estado Nacional brasileiro: o português.

\begin{abstract}
Based on the History of Linguistic Ideas, in its relation to the Discourse Analysis from a materialistic perspective, we analyze some aspects concerning the Brazilian language-spread policy, specifically, the imagery which signifies the lecturer of the Ministry of Foreign Affairs, officially defined as "the university teacher, of Brazilian nationality, who is dedicated to the teaching of the Portuguese language spoken in Brazil, and of the national culture and literature in foreign university institutions (BRASIL, 2006). It is possible to notice some heterogeneity in their work field, indicative of the fact that the lectureships are subordinated to the foreign institutions rather than to the Brazilian State. In addition, lecturers tend to be signified as representatives of Brazil, despite the polemics over what / whom they should represent. Therefore, through the national language, as a sign of the Brazilian culture, a place of cultural and/or diplomatic representation of Brazil is constructed.
\end{abstract}

Keywords: Portuguese as a foreign language; Brazilian language-spread policy; lectureship 


\section{REFERÊNCIAS}

AUROUX, S. A revolução tecnológica da gramatização. Campinas: Unicamp, 1992.

AUTHIER-REVUZ, J. Palavras incertas. As não coincidências do dizer. Campinas: Unicamp, 1998.

BRASIL. Presidência da República. Casa Civil. Subchefia para assuntos jurídicos. Lei n ${ }^{\circ}$. 6.815, de 19 de agosto de 1980, republicada pela determinação do artigo 11 da lei n. ${ }^{\circ} 6964$ de 09 de dezembro de 1981. Disponível em: <http://www.planalto.gov.br/ccivil_03/ leis/L6815.htm>. Acesso em: 08 dez. 2011.

. Constituição da República Federativa do Brasil, 5 out. 1988. Disponível em: <http://www.senado.gov.br/sf/legislacao/const/>. Acesso em: 22 fev. 2010.

. Presidência da República. Casa Civil. Subchefia para assuntos jurídicos. Emenda Constitucional n. 11, de 30 de abril de 1996. Disponível em: <http://www.planalto.gov.br/ccivil_03/ constituicao/emendas/emc/emc11.htm>. Acesso em: 08 dez. 2011.

.Ministério das Relações Exteriores. Gabinete do Ministro. Portaria n. ${ }^{\circ}$ 2, de 29 mar. 1999.Diário Oficial da União, Brasília, DF, 01 abr. 1999. Disponível em: <http://www.jusbrasil.com.br/ diarios/1097638/dou-secao-1-01-04-1999-pg-29>. Acesso em: 22 fev. 2010.

Ministério das Relações Exteriores. Gabinete do Ministro. Portaria Interministerial n ${ }^{\mathrm{o}}$ 01, de 20 de março 2006. Diário Oficial da União, Brasília, DF, 22 mar. 2006, p. 28. Disponível em: <http:// www.jusbrasil.com.br/diarios/505063/dou-secao-1-22-03-2006pg-28>. Acesso em: 22 fev. 2010.

- Certificado de Proficiência em Lingua Portuguesa para Estrangeiros: Manual do Examinando 2011/2. Brasília, DF: MEC/ INEP, 2011.

COURTINE, J.-J. Définition d'orientations théoriques et construction de procédures en analyse du discours. Philosophiques, 9 (2) : p. 239-264, oct. 1982.

DINIZ, L. R. A. Política linguística do Estado brasileiro na Contemporaneidade: a institucionalização de mecanismos de promoção da língua nacional no exterior. Tese (Doutorado em Linguística). Instituto de Estudos da Linguagem, Universidade Estadual de Campinas, 2012.

GOHN, C. O leitorado em Nova Delhi e o ensino de Português Lingua Estrangeira na perspectiva da diplomacia cultural. Universidade de Brasília: Centro de Estudos Avançados Multidisciplinares, Núcleo de Estudos Asiáticos, out. 2006. Disponível em: <http://www.unb. br/ceam/neasia/boletins/artigo_carlos_gohn041006.pdf $>$. Acesso em: 23 mar. 2009. 
GUIMARÃES, E. R. J. Texto e argumentação: um estudo de conjunções do português.Campinas: Pontes, 1987.

;ORLANDI, E. P. Apresentação. Identidade Lingüística. In: Pontes, 1996. (orgs). Lingua e cidadania: o português no Brasil. Campinas:

INDUSRKY, F. A fala dos quartéis e as outras vozes. Campinas: Unicamp, 1997.

ORLANDI, E. P. Apresentação. In:______ (org.). História das Idéias Lingüísticas: Construção do Saber Metalingüístico e Constituição da Língua Nacional. Campinas: Pontes; Cáceres: Unemat, 2001. p. 7-20.

PÊCHEUX, M. Análise automática do discurso (AAD-69). Tradução Eni P. Orlandi. In: GADET, F. \& HAK, T. (orgs). Por uma análise automática do discurso. Uma introdução à obra de Michel Pêcheux. Campinas: Unicamp, 1997. p. 61-161.

SCHAUMLOEFFEL, M. A. Informações sobre os Tabom e o Durbar por eles organizado. Visita do presidente Lula ao Gana, 2005. Disponível em: $<$ http://www.schaumloeffel.net/ghana/lula/Infos_sobre_os_Tabom_e_durbar.pdf $>$. Acesso em 16 fev. 2010.

SERRAVALLE DE SÁ, D. O leitorado brasileiro em Manchester: política linguística e o ensino de português como língua estrangeira. Cadernos de Letras da UFF, v. 39, p. 31-40, 2009. Disponível em: $<$ http://www.uff.br/cadernosdeletrasuff/39/artigo1.pdf $>$. Acesso em: 13 fev. 2010.

SILVA, J. F.; GUNNEWIEK, L. K. Portuguese and Brazilian efforts to spread Portuguese.International Journal of the sociology oflanguage, v. 95, p. 5-9, 1992. 